\title{
THE JOINT ACQUISITIONS LIST OF AFRICANA
}

The foint Acquisitions List of Africana ( $(\mathcal{A} A$ A $)$ has been compiled and published bi-monthly since January 1962 by the Melville J. Herskovits Library of African Studies at Northwestern University Library. $\mathscr{f} A L A$ reports the acquisition of monographs and serials by the principal libraries in the United States which collect Africana. The scope of $\exists A L A$ is restricted to those items published within the current and five preceding years of the issue date.

The $1978 f A L A$ production was computerized. A grant from the National Endowment for the Humanities and the Carnegie Corporation of New York aided in the creation of a machine-readable data base of Africana.

Annual cumulations of $\mathcal{F} A L A$ for $1978-80$ have been published by the $\mathrm{G}$. $\mathrm{K}$. Hall Company of Boston. In autumn 1984 Northwestern University Library published a cumulation of $\mathcal{F} A L A$ which covers the entire data base: that is, items listed in $\mathcal{Y} A L A$ from 1978 to 1983.

This cumulation is issued in two sections. The first contains an alphabetical listing by main entry and includes the most complete cataloguing available at the time of inclusion in $\varsubsetneqq A L A$. The section that follows is a geographical listing by area, region or country of most entries in the first section.

The foint Acquisitions List of Africana, 1978-83, a microfiche cumulation, may be purchased direct from the Africana Library, Northwestern University Library, Evanston, Il. 60201, USA. The price is $\$ 50$.

\section{INTERNATIONAL SYMPOSIUM OF THE AFRICAN HORN}

A symposium convened by the Institute of African Research and Studies, University of Cairo, 12613 Giza, Cairo, was held on 5-10 January 1985 . Seventyseven papers were presented on a wide range of topics, half by Egyptian scholars and half by scholars from France, Ethiopia, the USA, Somalia, Djibouti, Jordan, West Germany, Sweden, Uganda, the United Kingdom, Kenya, Canada and Italy and by some exiles. The seminar met as a whole for the morning sessions and divided into four groups for the afternoon session: $(a)$ Politics and economics, (b) Geography and natural resources, (c) History and (d) Anthropology, languages and culture. Further.information can be obtained from Professor $M$. A. Seoudy, Chairman and Dean of the Institute. The Institute aims to hold a second international symposium in 1987. 